\title{
Melatonin-loaded lipid-core nanocapsules protect against lipid peroxidation caused by paraquat through increased SOD expression in Caenorhabditis elegans
}

Mariele F. Charão ${ }^{1,2}$, Gabriela Goethel ${ }^{1,3}$, Natália Brucker ${ }^{1,4}$, Karina Paese ${ }^{3}$, Vera L. Eifler-Lima ${ }^{3}$, Adriana R. Pohlmann ${ }^{3}$, Silvia S. Guterres ${ }^{3}$ and Solange C. Garcia ${ }^{1,3^{*}}$

From 2nd Latin American Congress of Clinical and Laboratorial Toxicology

Porto Alegre, Brazil. 3-6 June 2018

\begin{abstract}
Background: Melatonin has been described in the literature as a potent antioxidant. However, melatonin presents variable, low bioavailability and a short half-life. The use of polymeric nanoparticulated systems has been proposed for controlled release. Thus, the purpose of this study was to investigate the action of melatonin-loaded lipid-core nanocapsules (Mel-LNC) in the antioxidant system of Caenorhabditis elegans, and the possible protective effect of this formulation against lipid peroxidation caused by paraquat (PQ).

Methods: The suspensions were prepared by interfacial deposition of the polymer and were physiochemically characterized. C. elegans N2 wild type and transgenic worm CF1553, muls84 [sod-3p::.gfp; rol6(su1006)] were obtained from the Caenorhabditis Genetics Center (CGC). The worms were divided into 5 groups: Control, PQ 0.5 $\mathrm{mM}, \mathrm{PQ} 0.5 \mathrm{mM}+$ Mel-LNC $10 \mu \mathrm{g} / \mathrm{mL}, \mathrm{PQ}+$ unloaded lipid-core nanocapsules (LNC), and PQ + free melatonin (Mel) $10 \mu \mathrm{g} / \mathrm{mL}$. The lipid peroxidation was assessed through thiobarbituric acid (TBARS) levels and the fluorescence levels of the transgenic worms expressing GFP were measured.
\end{abstract}

Results: The LNC and Mel-LNC presented a bluish-white liquid, with $\mathrm{pH}$ values of 5.56 and 5.69, respectively. The zeta potential was $-6.4 \pm 0.6$ and $-5.2 \pm 0.2$, respectively. The mean particle diameter was $205 \pm 4 \mathrm{~nm}$ and $203 \pm 3$ $\mathrm{nm}$, respectively. The total melatonin content was $0.967 \mathrm{mg} / \mathrm{ml}$. The TBARS levels were significantly higher in the PQ group when compared to the control group $(p<0.001)$. Mel-LNC reduced TBARS levels to similar levels found in the control group. Moreover, only Mel-LNC significantly enhanced the SOD-3 expression $(p<0.05)$. Mel-LNC was capable of protecting C. elegans from lipid peroxidation caused by PQ and this was not observed when free melatonin was used. Moreover, Mel-LNC increased the fluorescence intensity of the transgenic strain that encodes the antioxidant enzyme SOD-3, demonstrating a possible mechanism of protection from PQ-induced damage.

Conclusion: These findings demonstrated that melatonin, when associated with nanocapsules, had improved antioxidant properties and the protective activity against PQ-induced lipid peroxidation could be associated with the activation of antioxidant enzymes by Mel-LNC in C. elegans.

Keywords: Nanocapsules, Antioxidant, C. elegans, Herbicide, Superoxide dismutase

\footnotetext{
* Correspondence: solange.garcia@ufrgs.br

'Laboratory of Toxicology (LATOX), Federal University of Rio Grande do Sul,

Porto Alegre, Brazil, Porto Alegre, Rio Grande do Sul, Brazil

${ }^{3}$ Post-graduate Program in Pharmaceutical Sciences, Federal University of Rio

Grande do Sul, Porto Alegre, Brazil, Porto Alegre, RS, Brazil

Full list of author information is available at the end of the article
}

(c) The Author(s). 2019 Open Access This article is distributed under the terms of the Creative Commons Attribution 4.0 International License (http://creativecommons.org/licenses/by/4.0/), which permits unrestricted use, distribution, and reproduction in any medium, provided you give appropriate credit to the original author(s) and the source, provide a link to the Creative Commons license, and indicate if changes were made. The Creative Commons Public Domain Dedication waiver (http://creativecommons.org/publicdomain/zero/1.0/) applies to the data made available in this article, unless otherwise stated. 


\section{Background}

Melatonin, a hormone produced by the pineal glandule, has a high number of effects that are described in the literature, such as sedative, analgesic, and anticarcinogenic effects [1]. Also, it is reported that melatonin acts as a potent antioxidant and a reactive oxygen species (ROS) scavenger [2]. In addition, it has been observed that melatonin stimulates the activation of antioxidant enzymes, inhibiting pro-oxidative enzymes [3], and enhances the efficacy of mitochondrial functions [4, 5], regulating a large number of molecular pathways, including oxidative stress, inflammation, apoptosis, and cell death in different contexts [2-5]. However, melatonin presents a short half-life, variable and low bioavailability, and is quickly metabolized by the liver and is therefore not the best option for conventional formulations.

Several studies on nanotechnology have shown that this technology has a promising innovative drug release system, improving the properties of some molecules [69]. An improvement of the biological action of drugs has been demonstrated when associated with polymeric nanocapsules prepared with a biodegradable and biocompatible polymer, poly( $\varepsilon$-caprolactone) (PCL) [7]. Controlled systems delivery using polymeric nanoparticulated systems is being used to improve the properties of melatonin [8]. Schaffazick et al. [9] demonstrated that the encapsulation of melatonin, in polymeric nanocapsules, improved the antioxidant properties of this molecule as it caused a reduction in lipid peroxidation in the brain and liver of Wistar rats. Recently, our research group reported that melatonin-loaded lipid-core nanocapsules (Mel-LNC), prepared with PCL, presented protective effects against cytotoxicity and genotoxicity caused by paraquat (PQ) in the A549 cell line [10] and reduced ROS production in Caenorhabditis elegans exposed to PQ [11].

Paraquat (PQ) is an herbicide used in agriculture and it is highly toxic for humans and animals, being responsible for many cases of acute poisoning and death [12]. The main mechanism of toxicity of PQ is the generation of reactive oxygen species, leading to oxidative stress (OS). This process could result in deleterious effects such as lipid peroxidation, protein damage, genotoxicity, and NADPH oxidation, leading to the disruption of biochemical processes where NADPH is required [13-17].

Alternative models are a useful tool used in pharmacology and toxicological evaluations during initial studies. C. elegans is one of the best-established animal models and a very attractive experimental model due to its various characteristics: small size, short lifespan, rapid life cycle, translucent body, ability to self-fertilize and high reproductive rate, low cost, easiness to handle, and high degree of shared orthology with the human genome $[18,19]$. Moreover, it is possible to verify the possible mechanism of action through green fluorescent protein (GFP) labelled strains [20]. However, there is still a lack of studies concerning the possible mechanism of action of Mel-LNC. Therefore, this study aimed to investigate the activity of Mel-LNC in the antioxidant system in an alternative in vivo model of Caenorhabditis elegans, and the possible protective effect of this formulation against lipid peroxidation caused by $P Q$.

\section{Methods \\ Chemicals}

Sorbitan monostearate and melatonin were obtained from Sigma-Aldrich (Strasbourg, France). Biodegradable polymer poly( $\varepsilon$-caprolactone) $(\mathrm{PCL})(\mathrm{MW}=50,000)$ was supplied by Capa (Toledo, Ohio, USA). Caprylic/capric triglyceride and polysorbate 80 were obtained from Delaware (Porto Alegre, Brazil). Bacto-agar and bactopeptone were obtained from Becton Dickinson $\mathrm{BD}^{\circ}$ (New Jersey, USA) and HiMedia Laboratories ${ }^{\circledR}$ (Mumbai, India). Phosphoric acid and 2-thiobarbituric acid were purchased from Tedia Co (Fairfield, Ohio, USA) and Sprectrum Chemical Co (Gardena, California, USA), respectively. All other chemicals and solvents were analytical or pharmaceutical grade.

\section{Preparation and physicochemical characterization of the lipid-core nanocapsules}

The suspensions were prepared by interfacial deposition of the polymer [21, 22]. The organic phase was constituted of melatonin, sorbitan monostearate, capylic/capric triglyceride, and PCL, and then acetone was added in the aqueous phase, which was constituted of water and polysorbate 80 , under agitation. After that, the organic solvent and a fraction of the water were evaporated, and a white opaque liquid product was obtained. The final volume was adjusted to a theoretical final melatonin content of $1 \mathrm{mg} / \mathrm{mL}$. The blank formulation of unloaded lipid-core nanocapsules (LNC) was prepared as according to previously described without the addition of melatonin.

Particle size and distribution analyses were performed by dynamic light scattering using backscatter detection at $173^{\circ}$ (Zetasizer ZS, Malvern, UK) and volumeweighted mean diameter ([D4,3]) was determined by laser diffractometry at $25^{\circ} \mathrm{C}$ (Mastersizer 2000, Malvern, UK). A calibrated potentiometer (FiveEasy, Mettler Toledo, Brazil) was used to measure the $\mathrm{pH}$ values at $25^{\circ} \mathrm{C}$. The zeta potential was determined by electrophoretic light scattering (ZetasizerNano ZS model ZEN 3600, Malvern, USA).

The total amount of melatonin in the formulation was determined by a high-performance liquid chromatograph equipped with an ultraviolet-visible detector 
(Elmer Series 200 chromatograph), as according to Schaffazick et al. [9].

Encapsulation efficiency (EE\%) was determined indirectly by measuring free drug concentration $\left(\mathrm{C}_{\mathrm{f}}\right)$, according to the equation: $\mathrm{EE} \%=\left(C_{\mathrm{f}}-C_{\text {total }}\right) / C_{\text {total }} \times 100$, where $C_{\text {total }}$ is the total concentration of melatonin in the formulation. The formulation (Mel-LNC) was put into an ultrafiltration-centrifugation unit (Millipore, Amicon $^{\odot}$ Ultra, cutoff $10,000 \mathrm{Da}$ ), centrifuging (10 min, $15,300 \times \mathrm{g}$ ) and injecting the ultrafiltrate in the HPLC system as according to Schaffazick et al. [9].

\section{Strains}

The C. elegans N2 (wild-type) strains and the green fluorescent protein (GFP)-marked strain CF1553 [muls84] superoxide dismutase-3 (SOD::GFP) were maintained on nematode growth medium (NGM) plates seeded with Escherichia coli OP50 at $20^{\circ} \mathrm{C}$.

\section{Synchronization}

Gravid C. elegans were rinsed off the plates into centrifuge tubes and were lysed with a bleaching mixture (1\% $\mathrm{NaOCl} ; 0.25 \mathrm{M} \mathrm{NaOH}$ ), followed by flotation in a $30 \%$ sucrose solution $(\mathrm{m} / \mathrm{v})$ to separate the eggs. The eggs were washed with $\mathrm{M} 9$ buffer $\left(0.02 \mathrm{M} \mathrm{KH}_{2} \mathrm{PO}_{4}, 0.04 \mathrm{M}\right.$ $\mathrm{Na}_{2} \mathrm{HPO}_{4}, 0.08 \mathrm{M} \mathrm{NaCl}$, and $0.001 \mathrm{M} \mathrm{MgSO}_{4}$ ) and allowed to hatch overnight on NGM agar plates without bacteria [23].

\section{Treatment}

Without using bacteria, 2500 previously synchronized L1 worms were divided into 5 groups: Control, PQ $0.5 \mathrm{mM}$, PQ $0.5 \mathrm{mM}+$ Mel-LNC $10 \mu \mathrm{g} / \mathrm{mL}$, PQ $0.5 \mathrm{mM}+\mathrm{LNC}$, and PQ $0.5 \mathrm{mM}+$ free melatonin (Mel) $10 \mu \mathrm{g} / \mathrm{mL}$ in $0.5 \% \mathrm{NaCl}$ liquid media. The PQ + Mel-LNC, PQ + LNC, and $\mathrm{PQ}+$ Mel groups were pre-treated for $30 \mathrm{~min}$ at $20^{\circ} \mathrm{C}$, by constant agitation in a rotator, with Mel-LNC, $\mathrm{LNC}$, or Mel. After three washes with $0.5 \% \mathrm{NaCl}$, the worms were exposed to PQ $0.5 \mathrm{mM}$ for $30 \mathrm{~min}$ at $20^{\circ} \mathrm{C}$, by constant agitation. The PQ concentration chosen was based on a previous study [11], where $30 \%$ worm mortality and ROS enhancement was observed, at a concentration of PQ $0.5 \mathrm{mM}$, compared to the control group. The Mel-LNC and Mel concentrations were based on a previous study by our research group [11]. Additionally, worms treated with saline were used as a control. After PQ exposure, the worms were washed 3 times with $0.5 \%$ $\mathrm{NaCl}$ to remove the treatments and then transferred to NGM recovery plates inoculated with Escherichia coli OP50 for posterior assays.

\section{Thiobarbituric acid (TBARS) assay}

Thiobarbituric acid reactive substances (TBARS) were determined in the adult worms, $48 \mathrm{~h}$ after the end of treatment, as a marker of lipid peroxidation for the TBA (thiobarbituric acid) assay using a 1,1,3,3-tetramethoxypropane solution as malondialdehyde (MDA) standard [24]. The plates containing the worms were washed to remove the OP50. The nematodes were sonicated in turrax homogenizer at full amplitude for about $60 \mathrm{~s}$, in order to release the lipid and protein content. Then the content was centrifuged at $12,000 \mathrm{~g}$ for $5 \mathrm{~min}$. The supernatant was transferred to cryotubes where the TBARS reaction happened, with the addition of $0.1 \mathrm{M}$ phosphoric acid solution, $20 \mathrm{mM}$ sodium dodecyl sulfate solution, and $40 \mathrm{mM}$ 2-thiobarbituric acid solution. The reaction took place in a water bath for $1 \mathrm{~h}$ and $30 \mathrm{~min}$ under agitation at $100{ }^{\circ} \mathrm{C}$. Additionally, the samples were transferred to 96 well plates and their absorbance was read at $532 \mathrm{~nm}$ (Spectramax Me2; Molecular Devices LLC, Sunnyvale, CA, USA). The protein content of the samples was determined as according to Bradford [25].

\section{SOD fluorescence quantification}

The GFP expressing strain (CF1553 [muls84]) were subjected to acute exposure as described above. One thousand five hundred L1 worms were maintained in $100 \mu \mathrm{L}$ of saline buffer and transferred to a 96 well plate, where total GFP fluorescence was measured after $1 \mathrm{~h}$ of treatment using $485 \mathrm{~nm}$ excitation and $530 \mathrm{~nm}$ emission filters and a microplate reader (Spectramax Me2, Molecular DevicesLlC, Sunnyvale, CA, USA) at $20^{\circ} \mathrm{C}$. The results were expressed as the mean percentage of fluorescence intensity relative to control wells.

\section{Statistical analysis}

The results were expressed as the mean \pm standard deviation (SD). All figures were generated using GraphPad Prism (GraphPad Software, Inc.). The normality of data was tested by the Shapiro-Wilk test. The statistical analysis of significance was carried out using ANOVA, followed by the post hoc Bonferroni test in the SPSS Statistics software (version 22). Values of $p \leq 0.05$ were considered statistically significant.

\section{Results \\ Preparation and characterization of LNC}

Both formulations, LNC and Mel-LNC, presented a bluish-white liquid macroscopic aspect, with $\mathrm{pH}$ values ranging from 5.56 to 5.69. Particle sizing analysis by dynamic light scattering showed hydrodynamic diameters (Z-average) ranging from 200 to $209 \mathrm{~nm}$ (Table 1). The LNC and Mel-LNC presented low polydispersity indexes and a narrow distribution (Table 1). The zeta potential for the LNC and Mel-LNC was $-6.4 \pm 0.6$ and $-5.2 \pm$ 0.2 , respectively. The total melatonin content was 0.967 $\mathrm{mg} / \mathrm{ml}$ with an $\mathrm{EE} \%$ of $39.5 \%$. 
Table 1 Physicochemical characterization of the formulations

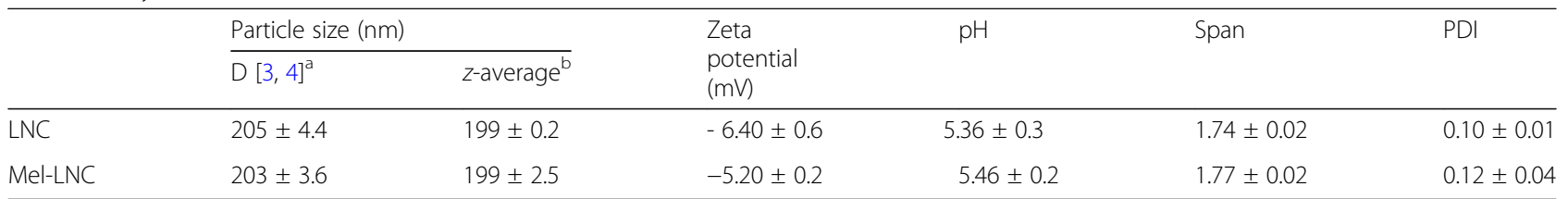

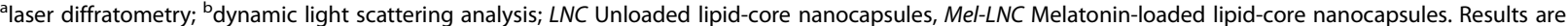
expressed as mean \pm SD. Number of samples?

\section{Effects of treatment with LNC, Mel-LNC, and Mel on PQ- induced lipid peroxidation}

As according to previous studies by our research group, $30 \%$ of the worms exposed to PQ $0.5 \mathrm{mM}$ were not alive $24 \mathrm{~h}$ after treatment, in contrast with the control group, where significant mortality was not observed. Pretreatment with Mel-LNC, before PQ exposure, was capable of significantly increasing the survival rate of the worms (about 25\%) when compared with the worms that did not receive the pre-treatment. The same was not observed when the worms were pre-treated with free melatonin.

Since lipid peroxidation is one of the toxic effects caused by $P Q$, we determined the TBARS levels in exposed worms. The lipid peroxidation assay demonstrated a significant increase in TBARS levels in worms exposed to PQ when compared to the control group (Fig. $1 ; p<0.001$ ). When the worms were pretreated with free melatonin and LNC, it was not possible to verify any protection from lipid peroxidation inflicted by $\mathrm{PQ}$, whereas Mel-LNC significantly decreased the TBARS levels induced by this herbicide (Fig. 1; p $<0.001$ ).

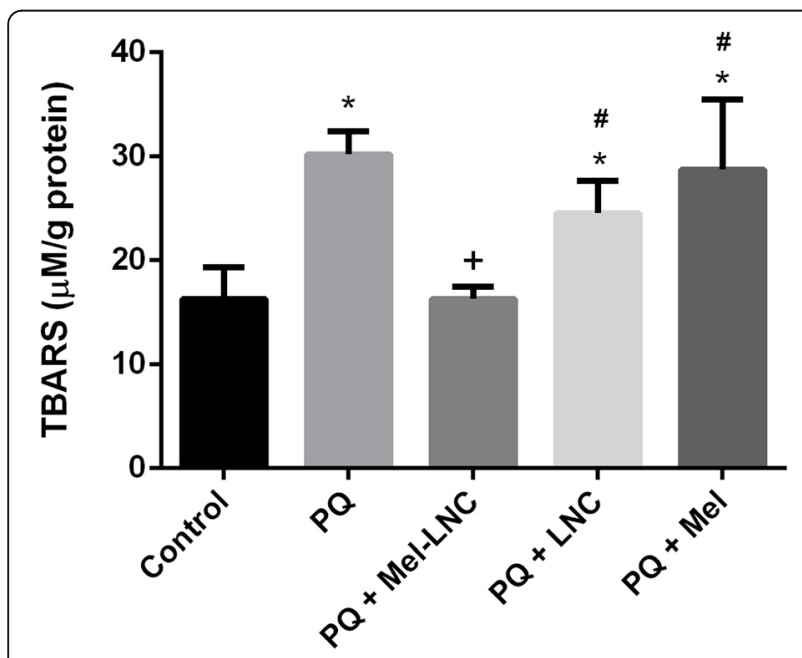

Fig. 1 Mel-LNC protects against PQ-induced lipid peroxidation. ${ }^{*} p<$ 0.001 compared to control group; ${ }^{+} p<0.001$ compared to PQ group; ${ }^{\mathrm{p}}<0.001$ compared to $\mathrm{PQ}+$ Mel-LNC group
Effects of treatment with Mel-LNC and Mel on GFPtagged protein levels

Regarding the possible mechanism of action of MelLNC, it was possible to observe that this formulation was responsible for the increase in fluorescence levels of the transgenic worms CF1553 (Fig. 2). This strain expresses the antioxidant enzyme superoxide dismutase-3 (SOD-3), which is responsible for the detoxification of reactive oxygen species (ROS), reducing the toxic effects induced by overproduction of ROS caused by PQ exposure. These effects were not observed when the worms were exposed to Mel, indicating that free melatonin is less effective in inducing SOD-3 expression, which is responsible for protecting the worms.

\section{Discussion}

In this study, it was demonstrated that Mel-LNC was capable of protecting $C$. elegans from lipid peroxidation caused by PQ. ROS overproduction is the main mechanism of PQ toxicity, inducing cell damage such as membrane injury, leading to the formation of products of lipid peroxidation, measured by TBARS assay. Additionally, Mel-LNC increased the fluorescence intensity of the transgenic strain CF1553 [muls84], which presented homology with antioxidant enzymes SOD-3 in humans. These findings demonstrated that activation of SOD-3

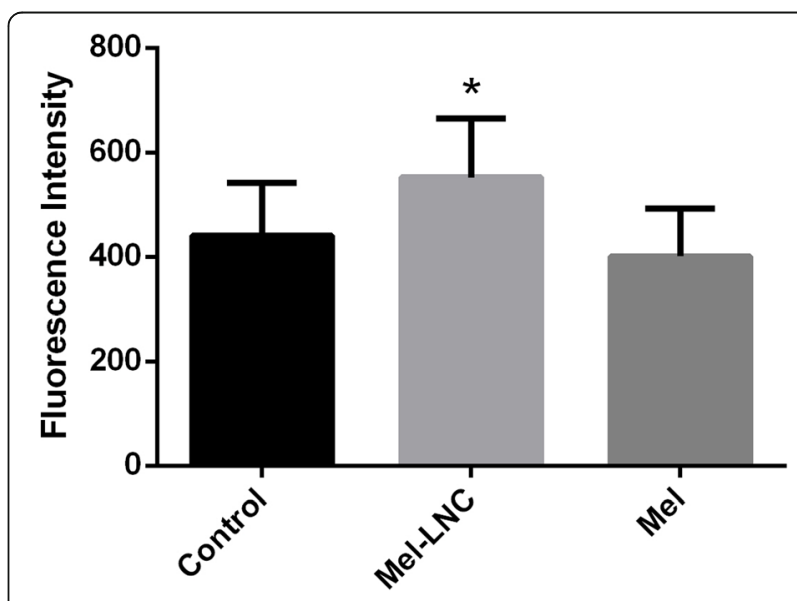

Fig. 2 Mel-LNC enhances superoxide dismutase (SOD) activity. ${ }^{*} p<$ 0.05 compared to control group 
could be involved in mediating Mel-LNC protection from PQ toxicity.

The characterization of the formulations used in this study (LNC and Mel-LNC) presented mean particle sizes similar to other studies that have used nanocapsules prepared by deposition of pre-formed polymer [26, 27]. The characterization of formulations is an essential step in toxicological and pharmacological studies, providing trustworthy results and conclusions. The polymer used in the formulation is responsible for the negative zeta potential values and these values were near zero because of the presence of polysorbate 80 . These characteristics make the formulation stable and avoid the formation of aggregates due to a steric repulse mechanism among the particles [27]. The low polydispersity index indicated the narrow particle distribution for both formulations (LNC and Mel-LNC). The total melatonin content in the MelLNC was $96.7 \%$, and the EE\% was $39.5 \%$, as according to previous studies that have used the same formulation $[10,11]$. Furthermore, previous studies have reported that encapsulation of some substances improves their biological action [28-30].

Melatonin and its metabolite are described as potent free radical scavengers [31]. Recently, it was demonstrated that exogenous melatonin reduced oxidative stress induced by hydrogen peroxide $\left(\mathrm{H}_{2} \mathrm{O}_{2}\right)$ through modulation of the ErK/Akt/NFkB pathway [32]. In addition, Garcia-Rubio et al. [33] showed that melatonin prevented cell damage in hepatocytes caused by PQ in an in vitro assay, confirming that melatonin is responsible for protecting against oxidative stress induced by this herbicide.

The toxic mechanism of PQ is mainly the formation of ROS leading to oxidative stress. PQ is responsible for inhibition of the electron transport chain and reacts with NADPH forming a PQ-radical. This radical reacts with oxygen and generates superoxide radicals. The antioxidant enzyme involved in this detoxification is superoxide dismutase, which converts superoxide anion to a relatively lower active form of hydrogen peroxide [34]. In $C$. elegans it is possible to investigate the involvement of this antioxidant enzyme with strain CF1553. The imbalance between oxidant species and antioxidants results in cell damage, such as lipid peroxidation. Due to its antioxidant capacity, melatonin has been described in cases of acute PQ intoxication [35-37]. In this study, it was possible to observe that Mel-LNC significantly reduced lipid peroxidation in worms exposed to $\mathrm{PQ}$ when compared to the $\mathrm{PQ}, \mathrm{PQ}+\mathrm{LNC}$, and $\mathrm{PQ}+\mathrm{Mel}$ groups. These findings reinforce one of the advantages of nanotechnology: improving the biological action of substances [38-40]. There are reports describing the biological action of LNC per se [41]; however, in this study, this was not observed.
All cellular components are susceptible to ROS action; however, the lipid membrane is one of the most affected. Higher levels of TBARS were observed in C. elegans when exposed to PQ compared to the control group (not exposed to PQ), and this is a good way to evaluate lipid peroxidation in this model [20]. The lipid peroxidation process leads to modifications in the structure and permeability of cell membranes and the formation of secondary products [42].

Melatonin is also described as a modulator of some antioxidant enzymes that help the body to eliminate reactive oxygen and nitrogen species [43]. Our results demonstrated that Mel-LNC significantly increases SOD-3 expression, which is crucial to protect the worms from superoxide radicals formed by $\mathrm{PQ}$. These results were in agreement with a recent study from Choudhary et al. [44], which demonstrated that melatonin was able to reduce lipid peroxidation and increase SOD and CAT activity in ewes. Moreover, the same has been observed in an in vitro assay with fresh hepatocytes, where there was a decrease in MDA levels and modulation of the antioxidant enzymes SOD and CAT in an oxidative stress model induced by $\mathrm{H}_{2} \mathrm{O}_{2}$ [33].

Wen et al. demonstrated that polydatin, a natural resveratrol glycoside, enhanced SOD-3::GFP expression in CF1553 worms, improving oxidative stress resistance in this model [45]. Moreover, an experimental study using two new molecules with antioxidant properties, 4-phenylselanyl- and 4-phenyltellanyl-7-chloroquinoline, showed the involvement of SOD-3 in preventing $\mathrm{PQ}$-induced mortality and lifespan reduction in C. elegans [20].

Tambara et al. [46] reported that extract obtained from pitanga fruit (a native Brazilian fruit) presented beneficial effects when $C$. elegans were exposed to stressors $\left(\mathrm{H}_{2} \mathrm{O}_{2}\right.$ and juglone), and was responsible for activating genes involved in antioxidant defenses, such as SOD-3. It was demonstrated that $\mathrm{Se}$ - and Texylofuranosides did not present toxic effects in concentrations that prevent and/or reverse the oxidative damage induced by manganese, as well as increasing SOD-3 expression [47].

The better effects of Mel-LNC observed in this study could be due to the mechanism of distribution of melatonin when this molecule is associated with polymeric nanocapsules and the characteristics of LNC per se. About $30-40 \%$ of melatonin is incorporated into the nanocapsules and this leads to a large load arrival of this molecule in cells, in this case in lipid membranes, where each nanocapsule present in the suspension can carry about 1200 molecules of melatonin. To our knowledge, this is the first time that the involvement of nanoencapsulated melatonin in SOD-3 expression has been demonstrated in C. elegans. These findings show that the 
protective activity against oxidative stress induced by PQ is closely associated with the increase of antioxidant enzyme SOD-3 by Mel-LNC in C. elegans.

\section{Conclusion}

Taken together, these results show that pre-treatment with MEL-LNC decreased lipid peroxidation probably through modulation of SOD enzymatic activity. Interestingly, these results were only observed in C. elegans treated with nanoencapsuled melatonin. Therefore, in this study Mel-LNC was more effective against paraquat damage, showing that nanotechnology presents a useful tool for improving the characteristics and biological properties of melatonin.

\section{Abbreviations}

EE\%: Encapsulation efficiency; $\mathrm{H}_{2} \mathrm{O}_{2}$ : Hydrogen peroxide; LNC: Unloaded lipid-core nanocapsules; LOO: Lipid peroxyl readical; MDA: Malondialdehyde; Mel: Free melatonin; Mel-LNC: Melatonin-loaded lipid-core nanocapsules; NADPH: Nicotinamide adenine dinucleotide phosphate; NGM: Nematode growth medium; OS: Oxidative stress; PCL: Poly( $\varepsilon$-caprolactone); PQ: Paraquat; ROS: Reactive oxygen species; SOD-3: Superoxide dismutase-3; TBA: Thiobarbituric acid; TBARS: Thiobarbituric acid reactive substances

\section{Acknowledgements}

We thank the Caenorhabditis Genetics Center (CGC) at the University of Minnesota for providing the worm strains.

\section{About this supplement}

This article has been published as part of BMC Pharmacology and Toxicology Volume 20 Supplement 1, 2019: Proceedings of Toxi-Latin 2018. The full contents of the supplement are available online at https:// bmcpharmacoltoxicol.biomedcentral.com/articles/supplements/volume-20supplement-1.

\section{Authors' contributions}

MFC performed the treatment and assays with C elegans, carried out the statistical analysis, and assisted in writing the manuscript. GG participated in the quantification of TBARS levels and the fluorescence microscopy analysis. NB contributed to the research design and data analysis, and assisted in writing the manuscript. KP, ARP, and SSG participated in the preparation and physicochemical characterization of the nanocapsules and assisted in writing the manuscript. VLE and SCG conceived and participated in the project design and coordination and corrected the manuscript. All authors contributed to writing the final manuscript and approved it.

\section{Funding}

This study was supported by FAPERGS/CNPq (16/2551-0000467-6) and INCT/ CNPq-MCTI (465787/2014-8). A PhD research fellowship for MF Charão was provided by CAPES. SC Garcia, SS Guterres, AR Pohlmann, and V Eifler-Lima are recipients of CNPq research fellowships and grants. Publication costs are funded by SC Garcia's CNPq fellowship.

\section{Availability of data and materials}

The data for this study are available from the corresponding author on reasonable request.

\section{Ethics approval and consent to participate}

Not applicable.

\section{Consent for publication}

Not applicable.

\section{Competing interests}

The authors declare that they have no competing interests.

\section{Author details}

'Laboratory of Toxicology (LATOX), Federal University of Rio Grande do Sul, Porto Alegre, Brazil, Porto Alegre, Rio Grande do Sul, Brazil. 'Laboratory of Analytical Toxicology, Feevale University, Novo Hamburgo, Brazil, Novo Hamburgo, RS, Brazil. ${ }^{3}$ Post-graduate Program in Pharmaceutical Sciences, Federal University of Rio Grande do Sul, Porto Alegre, Brazil, Porto Alegre, RS, Brazil. ${ }^{4}$ Department of Physiology and Pharmacology, Federal University of Santa Maria, Porto Alegre, Brazil, Santa Maria, RS, Brazil.

Published: 19 December 2019

\section{References}

1. Cos $\mathrm{S}$, et al. Influence of melatonin on invasive and metastatic properties of MCF-7 human breast cancer cells. Cancer Res. 1998;58:4383-90.

2. Ding $K$, et al. Melatonin stimulates antioxidant enzymes and reduces oxidative stress in experimental traumatic brain injury: the Nrf2-ARE signaling pathway as a potential mechanism. Free Radic Biol Med. 2014;73C: $1-11$.

3. Galano A, Tan D, Reiter RJ. Melatonin: a versatile protector against oxidative DNA damage. Molecules. 2018;23:530-66.

4. Chabra A, Shokrzadeh M, Naghshvar F, Salehi F, Ahmadi A. Melatonin ameliorates oxidative stress and reproductive toxicity induced by cyclophosphamide in male mice. Hum Exp Toxicol. 2014;33:185-95.

5. Olayaki LA, Alagbonsi IA, Abdulrahim AH, Adeyemi WJ, Bakare M, Omeiza N. Melatonin prevents and ameliorates lead-induced gonadotoxicity through antioxidative and hormonal mechanisms. Toxicol Ind Health. 2018. https:// doi.org/10.1177/0748233718773508.

6. Pohlmann AR, Fonseca FN, Paese K, Detoni CB, Coradini K, Beck RC, et al. Poly(-caprolactone) microcapsules and nanocapsules in drug delivery. Expert Opin Drug Deliv. 2013;10:623-38.

7. Zhai Q, Duan H, Wang Y, Huang C, Niu Y, Dai Y, et al. Genetic damage induced by organic extract of coke oven emissions on human bronchial epithelial cells. Toxicol In Vitro. 2012;26:752-8.

8. Schaffazick SR, Pohlmann AR, Guterres SS. Nanocapsules, nanoemulsion and nanodispersion containing melatonin: preparation, characterization and stability evaluation. Pharmazie. 2007;62:354-60.

9. Schaffazick SR, Pohlmann AR, de Cordova CA, Creczynski-Pasa TB, Guterres SS. Protective properties of melatonin-loaded nanoparticles against lipid peroxidation. Int J Pharm. 2005;289:209-13.

10. Charão MF, Baierle M, Gauer B, Goethel G, Fracasso R, Paese K, et al. Protective effects of melatonin-loaded lipid-core nanocapsules on paraquatinduced cytotoxicity and genotoxicity in a pulmonary cell line. Mutat Res Genet Toxicol Environ Mutagen. 2015;784-785:1-9.

11. Charão MF, Souto C, Brucker N, Barth A, Jornada DS, Fagundez D, et al. Caenorhabditis elegans as an alternative in vivo model to determine oral uptake, nanotoxicity, and efficacy of melatonin-loaded lipid-core nanocapsules on paraquat damage. Int J Nanomedicine. 2015;10:5093-106.

12. Zerin T, Kim YS, Hong SY, Song HY. Protective effect of methylprednisolone on paraquat-induced A549 cell cytotoxicity via induction of efflux transporter, P-glycoprotein expression. Toxicol Lett. 2012;208:101-7.

13. Kushwaha S, Vikram A, Trivedi PP, Jena GB. Alkaline, Endo III and FPG modified comet assay as biomarkers for the detection of oxidative DNA damage in rats with experimentally induced diabetes. Mutat Res. 2011;726: 242-50.

14. Suntres ZE. Role of antioxidants in paraquat toxicity. Toxicol. 2002;180:65-77.

15. Yeh ST, Guo HR, Su YS, Lin HJ, Hou CC, Chen HM. Protective effects of Nacetylcysteine treatment post acute paraquat intoxication in rats and in human lung epithelial cells. Toxicol. 2006;223:181-90.

16. Mitsopoulos P, Suntres ZE. Cytotoxicity and gene array analysis of alveolar epithelial A549 cells exposed to paraquat. Chem Biol Interact. 2010;188:42736.

17. Mehdi SH, Qamar A. Paraquat-induced ultrastructural changes and DNA damage in the nervous system is mediated via oxidative-stress-induced cytotoxicity in Drosophila melanogaster. Toxicol Sci. 2013;134:355-65.

18. Pinkas A, Martins AC Jr, Aschner M. C. elegans - an emerging model to study metal-induced RAGE-related pathologies. Int J Environ Res Public Health. 2018. https://doi.org/10.3390/ijerph15071407.

19. Ruszkiewicz JA, Pinkas A, Miah MR, Weitz RL, Lawes MJA, Akinyemi AJ, et al. C. elegans as a model in developmental neurotoxicology. Toxicol Appl Pharmacol. 2018;354:126-35. 
20. Salgueiro WG, Goldani BS, Peres TV, Miranda-Vizuete A, Aschner M, Rocha JBT, et al. Insights into the differential toxicological and antioxidant effects of 4-phenylchalcogenil-7-chloroquinolines in Caenorhabditis elegans. Free Radical Bio Med. 2017:110:131-41.

21. Jornada DS, Fiel LA, Bueno K, Gerent JF, Petzhold CL, Beck RCR, et al. Lipidcore nanocapsules: mechanism of self-assembly, control of size and loading capacity. Soft Matter. 2012;8:6646-55.

22. Jager A, Stefani V, Guterres SS, PohImann AR. Physico-chemical characterization of nanocapsule polymeric wall using fluorescent benzazole probes. Int J Pharm. 2007;338:297-305.

23. Avila DS, Benedetto A, Au C, Manarin F, Erikson K, Soares FA, et al. Organotellurium and organoselenium compounds attenuate Mn-induced toxicity in Caenorhabditis elegans by preventing oxidative stress. Free Radic Biol Med. 2012;52:1903-10.

24. Ohkawa H, Ohishi N, Yagi K. Assay for lipid peroxides in animal tissues by thiobarbituric acid reaction. Anal Biochem. 1979;95:351-8.

25. Bradford MM. A rapid and sensitive method for the quantitation of microgram quantities of protein utilizing the principle of protein-dye binding. Anal Biochem. 1976;72:248-54.

26. Venturini CG, Jager E, Oliveira CP, Bernardi A, Battastini AMO, Guterres SS, et al. Formulation of lipid core nanocapsules. Colloids Surf A Physicochem Eng Asp. 2011;375:200-8.

27. Poletto FS, Jäger $E$, Cruz L, Pohlmann AR, Guterres SS. The effect of polymeric wall on the permeability of drug-loaded nanocapsules. Mat Sci Eng C-Biomim. 2008;28:472-8.

28. Carletto B, Berton J, Ferreira TN, Dalmolin LF, Paludo KS, Mainardes RM, et al. Resveratrol-loaded nanocapsules inhibit murine melanoma tumor growth. Colloid Suface B. 2016;144:65-72.

29. Lee CH, Li YJ, Huang CC, Lai JY. Poly(E-caprolactone) nanocapsule carriers with sustained drug release: single dose for long-term glaucoma treatment. Nanoscale. 2017:0:1-7

30. Rigo LA, Carvalho-Wodarz CS, Pohlmann AR, Guterres SS, Schneider-Daum $\mathrm{N}$, Lehr CM, et al. Nanoencapsulation of a glucocorticoid improves barrier function and anti-inflammatory effect on monolayers of pulmonary epithelial cell lines. Eur J Pharm Biopharm. 2017. https://doi.org/10.1016/j. ejpb.2017.05.006.

31. Bonilla E, Medina-Leendertz S, Villalobos V, Molero L, Bohórquez AB. Paraquat-induced oxidative stress in Drosophila melanogaster: effects of melatonin, glutathione, serotonin, minocycline, lipoic acid and ascorbic acid. Neurochem Res. 2006:31:1425-32.

32. Moniruzzaman M, Ghosal I, Das D, Chakraborty SB. Melatonin ameliorates $\mathrm{H}_{2} \mathrm{O}_{2}$-induced oxidative stress through modulation of Erk/Akt/NFkB pathway. Biol Res. 2018;51:17.

33. Garcia-Rubio L, Matas P, Miguez MP. Protective efect of melatonin on paraquat-induced cytotoxicity in isolated rat hepatocytes. Hum Exp Toxicol. 2005;24:475-80.

34. Melchiorri D, Reiter RJ, Sewerynek E, Hara M, Chen L, Nisticò G. Paraquat toxicity and oxidative damage. Reduction by melatonin. Biochem Pharmacol. 1996:51:1095-9.

35. Melchiorri D, Reiter RJ, Attia AM, Hara M, Burgos A, Nistico G. Potent protective effect of melatonin on in vivo paraquat-induced oxidative damage in rats. Life Sci. 1995;56:83-9.

36. Gocgeldi E, Uysal B, Korkmaz A, Ogur R, Reiter RJ, Kurt B, et al. Establishing the use of melatonin as an adjuvant therapeutic against paraquat-induced lung toxicity in rats. Exp Biol Med (Maywood). 2008;233:1133-41.

37. Singhal NK, Srivastava G, Patel DK, Jain SK, Singh MP. Melatonin or silymarin reduces maneb- and paraquat-induced Parkinson's disease phenotype in the mouse. J Pineal Res. 2011;50:97-109.

38. Zanotto-Filho A, Coradini K, Braganhol E, Schröder R, de Oliveira CM Simões-Pires A, et al. Curcumin-loaded lipid-core nanocapsules as a strategy to improve pharmacological efficacy of curcumin in glioma treatment. Eur J Pharm Biopharm. 2013;83:156-67.

39. Bernardi A, Frozza RL, Meneghetti A, Hoppe JB, Battastini AMO, Pohlmann $A R$, et al. Indomethacin-loaded lipid-core nanocapsules reduce the damage triggered by Abeta1-42 in Alzheimer's disease models. Int J Nanomedicine. 2012;7:4927-42

40. Schaffazick SR, Siqueira IR, Badejo AS, Jornada DS, Pohlmann AR, Netto CA et al. Incorporation in polymeric nanocapsules improves the antioxidant effect of melatonin against lipid peroxidation in mice brain and liver. Eur $\rfloor$ Pharm Biopharm. 2008:69:64-71.
41. Bender EA, Cavalcante MF, Adorne MD, Colome LM, Guterres SS, Abdalla DS, et al. New strategy to surface functionalization of polymeric nanoparticles: one-pot synthesis of scFv anti-LDL(-)-functionalized nanocapsules. Pharm Res. 2014:31:2975-87.

42. Ayala A, Muñoz MF, Argüelles S. Lipid peroxidation: production, metabolism, and signaling mechanisms of malondialdehyde and 4-Hydroxy-2-Nonenal. Oxid Med Cell Longev. 2014. https://doi.org/10.1155/2014/360438.

43. Ceraulo L, Ferrugia M, Tesoriere L, Segreto S, Livrea MA, Turco LV. Interactions of melatonin with membrane models: portioning of melatonin in AOT and lecithin micelles. J Pineal Res. 1999;26:108-12.

44. Choudhary PK, Ishwar AK, Kumar R, Niyogi D, Kumar M. Effect of exogenous melatonin and different photoperiods on oxidative status and antioxidant enzyme activity in Chhotanagpuri ewe. Veterinary World. 2018;11:130-4.

45. Wen H, Gao X, Qin J. Probing the anti-aging role of polydatin in Caenorhabditis elegans on a chip. Integr Biol. 2014;6:35-43.

46. Tambara AL, Moraes LS, Dal Forno AH, Boldori JR, Soares ATG, Rodrigues CF, et al. Purple Pitanga fruit (Eugenia uniflora L.) protects against oxidative stress and increase the lifespan in Caenorhabditis elegans via the DAF-16/ FOXO pathway. Food Chem Toxicol. 2018. https://doi.org/10.1016/j.fct.2018. 07.057

47. Wollenhaupt SGN, Soares AT, Salgueiro WG, Noremberg S, Reis G, Viana C, et al. Seleno- and Telluro-xylofuranosides attenuate Mn-induced toxicity in C. elegans via the DAF-16/FOXO pathway. Food Chem Toxicol. 2014;64:192-9.

\section{Publisher's Note}

Springer Nature remains neutral with regard to jurisdictional claims in published maps and institutional affiliations.
Ready to submit your research? Choose BMC and benefit from:

- fast, convenient online submission

- thorough peer review by experienced researchers in your field

- rapid publication on acceptance

- support for research data, including large and complex data types

- gold Open Access which fosters wider collaboration and increased citations

- maximum visibility for your research: over $100 \mathrm{M}$ website views per year

At $\mathrm{BMC}$, research is always in progress.

Learn more biomedcentral.com/submissions 